\title{
Environmental Sounds Enhance Cortical Responses Related to a Serial Arithmetic Task
}

\author{
Koichiro Fujimaki1 ${ }^{*}$, Hidenori Takemoto' ${ }^{1}$, Shigeru Morinobu ${ }^{2}$ \\ ${ }^{1}$ Faculty of Health and Welfare, Prefectural University of Hiroshima, Hiroshima, Japan \\ ${ }^{2}$ Department of Psychiatry, Kochi University School of Medicine, Kochi, Japan \\ Email: ${ }^{*}$ fujimaki@pu-hiroshima.ac.jp
}

Received 5 February 2014; revised 1 March 2014; accepted 18 March 2014

Copyright (C) 2014 by authors and Scientific Research Publishing Inc.

This work is licensed under the Creative Commons Attribution International License (CC BY). http://creativecommons.org/licenses/by/4.0/

(c) (i) Open Access

\begin{abstract}
In this study, we used near-infrared spectroscopy (NIRS) to examine the effects of environmental sounds on performance of a serial arithmetic task. Subjects included 6 males and 15 females aged 21 or 22 years. All subjects were required to perform a serial arithmetic task according to the Uchida-Kraepelin performance test. We used four environmental conditions: hubbub sound, forest sound, traffic noise, and a silent control condition. During the serial arithmetic task, we also measured hemodynamic changes in the frontal cortex using NIRS to assess the effects of environmental sounds on brain function during the serial arithmetic task. Results showed that exposure to environmental sounds did not enhance or detract from task performance speed in a serial arithmetic task performance when compared with results obtained upon exposure to silence. However, environmental sounds enhanced cortical responses during the serial arithmetic task. Our results reveal differences in activation of the prefrontal cortex under different sound conditions, which may help increase our understanding of the potential effects of environmental sounds.
\end{abstract}

\section{Keywords}

Environmental Sound, Cortical Response, Near-Infrared Spectroscopy

\section{Introduction}

Humans are constantly exposed to a multitude of sounds, and complete silence is somewhat rare. Characterization of sounds as pleasant or unpleasant depends on the individual. For example, a forest sound consisting of

${ }^{*}$ Corresponding author.

How to cite this paper: Fujimaki, K., Takemoto, H., \& Morinobu, S. (2014). Environmental Sounds Enhance Cortical Responses Related to a Serial Arithmetic Task. Psychology, 5, 828-839. http://dx.doi.org/10.4236/psych.2014.58094 
chirping of small birds or a small running stream is considered pleasant, and sounds of nature in a virtual reality forest enhance stress recovery (Annerstedt et al., 2013). Furthermore, it is reported that nature sounds alone can provide an effective method of reducing potentially harmful physiological responses due to anxiety (Saadatmand et al., 2013). On the other hand, in a time of extraordinary efforts toward environmental protection, protection against "unwanted sounds" has become crucial. For example, traffic noise, which is steadily increasing, is regarded as an important environmental health problem, and the role of road traffic noise as stressor has been extensively investigated (Babisch, 2005; Babisch et al., 2005; Bluhm et al., 2004; Jarup et al., 2005). The correlation between annoying sounds, including chatter, was studied, and a significant negative effect of noise on students' schoolwork was shown (Lundquist et al., 2000). In a background of children's chatter, greater cognitive resources are required, and this background noise has been shown to be associated with reduced task performance (Howard et al., 2010). The potential of environmental noise to influence cognitive performance has intrigued researchers, therapists, and educators. Little research, however, has been conducted to investigate the effects of environmental noise and auditory distractions on cortical responses during performance. It was suggested that background noise affected P300 latency (Salisbury et al., 2002). In addition, recent research suggested that significant performance degradation was observed for near-infrared spectroscopy NIRS-based brain-computer interfaces based on prefrontal cortex activation (e.g., via music imagery) (Falk et al., 2010). This reduction in accuracy may be due to factors such as 1) the performance of mental tasks being severely affected by environmental noise (Banbury, 1998; Cassidy \& MacDonald, 2007; Flaten et al., 2005; Furnham \& Strbac, 2002; Gumenyuk et al., 2004) or 2) the prefrontal cortex being involved in the processing of distracting auditory stimuli (Boly et al., 2004; Engelien et al., 2000).

NIRS has been recently investigated as a noninvasive means of assessing functional activity in the brain via measured hemodynamic responses (Sitaram et al., 2007). Unlike electroencephalograms (EEGs), however, NIRS measurements do not require cumbersome skin preparation and electrode gels. NIRS has been used for the non-invasive measurement of concentration changes in oxygenated hemoglobin (oxy-Hb), deoxygenated hemoglobin (deoxy-Hb), and total hemoglobin (total-Hb) related to brain functions. NIRS determines the properties of the brain tissue by transmitting near-infrared electromagnetic radiation (650 - $950 \mathrm{~nm}$ wave lengths) through the skull and comparing the intensities of the returning and incident light. Because the fraction of light absorbed versus the fraction transmitted is dependent on the concentrations of chromophores, NIRS can be used to assess hemodynamic responses in regions such as the motor cortex (using motor imagery tasks (Sitaram et al., 2007)) and the prefrontal cortex (using music imagery (Blood \& Zatorre, 2001), mental arithmetic (Villringer \& Chance, 1997), or preference tasks (Luu \& Chau, 2009)). In regard to changes in oxy-Hb induced by a serial arithmetic task, a previous study suggested that oxy-Hb significantly increased just after the initiation of calculation and returned to initial levels $3 \mathrm{~min}$ after the calculation in the first half of the task (Watanabe et al., 2002). Furthermore, in a recent meta-analysis including 53 fMRI data sets on brain activation during mental arithmetic, three distinct regions in the prefrontal cortex that contribute to performance on mental arithmetic were identified (Arsalidou \& Taylor, 2011).

Based on an examination of the above-mentioned studies, we set up the hypotheses in the present study. Background noise has been shown to be associated with reduced task performance (Howard et al., 2010), and the prefrontal cortex is involved in the processing of distracting auditory stimuli (Boly et al., 2004; Engelien et al., 2000). Furthermore oxy-Hb significantly increases just after the initiation of calculation (Watanabe et al., 2002). Considering these previous studies, we hypothesized that environmental sounds would be associated with slowed psychomotor responses during serial arithmetic task performance, mediated by the processing of auditory stimuli. In this study, we used NIRS to investigate the effects of environmental sounds on the prefrontal cortex during an intelligence task.

\section{Methods}

\subsection{Subjects}

Twenty-one healthy volunteers (males, 6; females, 15) participated in this study (mean age, $21.7 \pm 0.47$ years; range, 21 - 22 years). All subjects were determined to be right-handed using the Edinburgh Handedness Inventory Scale (Oldfield, 1971). Participants were recruited from the Prefectural University of Hiroshima. Participants were recruited primarily via emails and recruitment posters. All participants were students. All participants live in a radius $1 \mathrm{~km}$ around the Prefectural University of Hiroshima, which is away from major roadways, fac- 
tories etc., that is, not exposed to noise. Participants also had to be able and willing to attend the research. No subject had a history of neurological disorder, major psychiatric disorder, substance abuse, head injury, or major physical illness, or was using any psychotropic medications at the time of the study. We screened subjects for hearing impairment, confirming that all subjects had hearing levels of less than $20 \mathrm{~dB}$ at two frequencies tested (1, $4 \mathrm{kHz}$ ). This study was approved by the Prefectural University of Hiroshima. Written informed consent was obtained from each subject prior to the study.

\subsection{Activation Task}

The activation task consisted of a 30-s pre-task baseline, a serial arithmetic task, and a 70-s post-task baseline. Each subject sat on a comfortable chair in a quiet room and was ordered to keep his/her head as immobile as possible and not to speak. The task was a serial addition test (Sugimoto et al., 2009), which required subjects to perform calculations as fast and accurately as possible within $15 \mathrm{~min}$. This was achieved using pre-printed paper containing 15 lines of random, single-digit, horizontally aligned numbers. For each minute of the test, the subject was instructed to begin a new line regardless of their position on the current line. Each line contained an excess of calculations such that the subjects were not able to finish any line for a particular minute before being prompted to move on to the start of the next minute by the examiner's prompting. In order to rule out learning effects, all participants were trained by performing five lines of calculations.

\subsection{Sound Conditions}

We used four types of sound conditions: hubbub sound, forest sound, traffic noise, and a silent control condition. We recorded hubbub sound that consisted of irrelevant speech and kitchen noise in the Prefectural University of Hiroshima school cafeteria. Similarly, we recorded forest sound that consisted of bird vocalizations in forests near the Prefectural University of Hiroshima and traffic noise that was generated by a major roadway (Japan National Route 2). Four sessions were conducted per subject in a counter-balanced order. Seven days passed between each session for each subject. The experiment was conducted in a soundproofed room maintained at $24^{\circ} \mathrm{C}$ and $50 \%$ humidity. Sounds were presented by two loudspeakers placed $1 \mathrm{~m}$ in front of the participants' ears with a mean sound level of 50 decibel $(\mathrm{dB})$. A decibel meter was used to ensure that participants were presented with stimuli matched for a sound level of $50 \mathrm{~dB}$.

\subsection{NIRS Measurement}

Changes in the concentration of oxy-Hb and deoxy-Hb were measured using a 24-channel NIRS machine (ETG-100, Hitachi Medical Corporation, Tokyo, Japan) at 2 wavelengths of near-infrared light (i.e., 780 and $830 \mathrm{~nm}$ ). Absorption was measured, and oxy-Hb and deoxy-Hb were calculated. The distance between the pair of emission and detector probes was $3.0 \mathrm{~cm}$, and we defined each measuring area between pairs of source-detector probes as one "channel". It is assumed that a machine, in which the source-detector spacing is $3.0 \mathrm{~cm}$, was able to measure points at a depth of $2-3 \mathrm{~cm}$ from the scalp (Okada \& Delpy, 2003). The probes of the NIRS machine were placed on the subject's bilateral frontal region (Figure 1). The frontal probes measured Hb concentration changes at 24 measurement points in a $6 \times 15 \mathrm{~cm}$ area, with the lowest probes positioned along the Fp1-Fp2 line according to the international 10/20 system used in electroencephalography (Okamoto et al., 2004). The absorption of near-infrared light was measured with a time resolution of $0.1 \mathrm{~s}$. To remove slow baseline drifts and high-frequency instrument noise in oxy-Hb and deoxy-Hb, raw NIRS data were pre-processed. Using analysis software Hitachi ETG-100 OT system (Hitachi Medical Co., Tokyo, Japan), a moving average filter with a time window of $5 \mathrm{~s}$ and a band pass filter with cut-off frequencies of 0.02 and $0.8 \mathrm{~Hz}$ were applied. To reduce additional spike-like noise in the continuous data (e.g., head motion artifacts), the signal was improved by applying a method based on the assumption that oxy- $\mathrm{Hb}$ and deoxy- $\mathrm{Hb}$ are negatively correlated (Cui et al., 2010). This way, the data were also cleaned from potential artifacts due to the arithmetic task. Resulting data consisted of solely one parameter, that is, a linear combination of oxy- $\mathrm{Hb}$ and deoxy-Hb representing the hemodynamic response. Larger values thereby indicated higher cortical activation.

\subsection{Analytical Methods}

We calculated the mean number of correct answers per line on the serial arithmetic task, and used one-way 


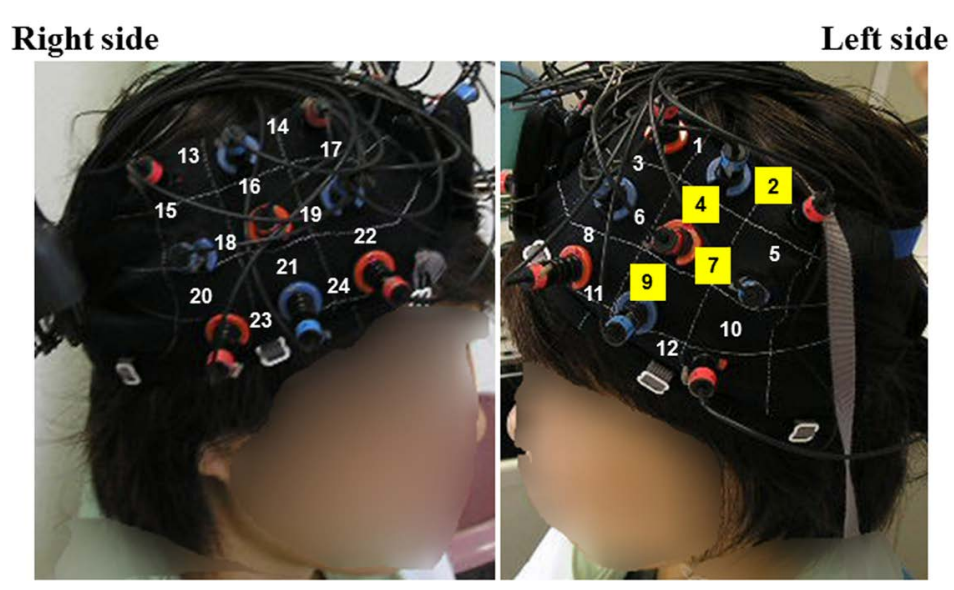

Figure 1. Probe setting and channels showing significant hemodynamic change. Yellow area indicates a channel showing significant differences in hemodynamic change comparing to a silent control conditions.

analysis of variance (ANOVA) with Bonferroni's test to compare the results of the four groups. Bonferroni corrections were used to minimize the risk of falsely identifying significant differences due to multiple comparisons.

The hemodynamic waveforms of oxy-Hb, deoxy-Hb, and total-Hb of each of the 24 channels were obtained by multiplying the changes in the absorption of the light by the length of the light path (unit: $\mathrm{mmol} \times \mathrm{mm}$ ).

The analysis focused on changes in oxy- $\mathrm{Hb}$, which were defined as the mean concentrations of oxy- $\mathrm{Hb}$. Changes in oxy-Hb were assumed to reflect cognitive activation more directly than deoxy-Hb changes, as shown by their stronger correlation with blood-oxygenation level dependent signals measured by functional magnetic resonance imaging (fMRI) (Strangman et al., 2002). Mean hemoglobin changes were determined using the paired t-test to examine whether the signal changes due to activation were statistically significant. Further, measurement positions with significant mean values were identified as activation positions.

The optical signal measured in each trial was transformed into a time series of optical topography signals based on the modified Beer-Lambert law (Maki et al., 1995). We used oxy-Hb signals as the representative optical topography signals in this study. The continuous stream data were divided into blocks that each consisted of a 30-s pre-task period, a 900-s task period, and a 70-s post-task period for further analysis. Furthermore, we smoothed the data points using a moving average filter with a time window of $5 \mathrm{~s}$ and estimated the first-degree baseline value for each block and each channel. The obtained data were analyzed using the "integral mode". The pre-task baseline was determined as the mean across the last 10-s of the 30-s pre-task period; the post-task baseline was determined as the mean across the last 5-s of the 70-s post-task period. Linear fitting was applied to the data between these two baselines. For each subject, the mean change in the concentration of oxy-Hb was calculated for each sound condition and each channel. The average changes in oxy-Hb during each task were used for statistical analysis. The comparison of means among the four groups was performed by one-way factorial ANOVA. It was followed by a post hoc Dunnet two-sided comparison.

The grand average waveforms of the oxy-Hb concentration changes were obtained for all the subjects, based on each subject's waveforms in all 24 channels.

All analytical values were considered significantly different at $p<0.05$. Statistical analyses were performed using PASW Statistics 18.0 software (SPSS Japan Inc., Tokyo, Japan).

\section{Results}

All subjects were able to perform the serial arithmetic task. The mean number of correct answers per line on the serial arithmetic task is shown in Figure 2. The mean number of correct answers per line with the hubbub sound, forest sound, traffic noise, and silent control condition was $70.7 \pm 2.8,70.6 \pm 2.4,72.1 \pm 2.7$, and $68.1 \pm 2.9$, respectively. There were no significant differences between the three environmental sounds or the silent control condition.

All channel positions yielded statistical significance, indicating cortical activation, and reached the $5 \%$ level of significance with the t-test. 


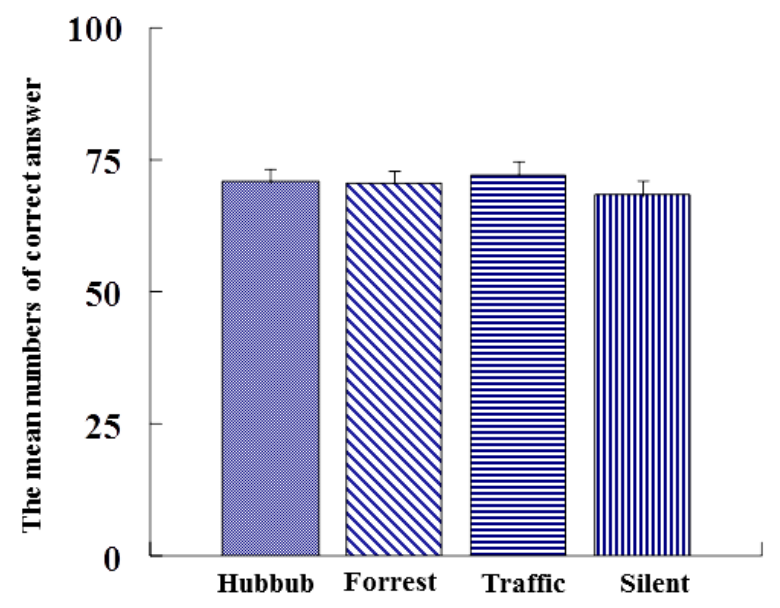

Figure 2. The mean numbers of correct answer per line on the serial arithmetic task (mean $\pm \mathrm{SE}$ ) grouped for sound condition. The scores of individuals in the hubbub sound, the forest sound and the traffic noise were not significantly higher than those in the silent control conditions.

The grand average waveforms of hemodynamic changes with a serial arithmetic task are shown in Figure 3. In the serial arithmetic task, the hubbub sound, the forest sound, and traffic noise were associated with a significantly higher number of left lateral activation positions in the frontal cortex (Figure 3).

Oxy-Hb measurements are shown in Figure 4. The hemodynamic changes in Channels 2, 4, 7, and 9 with the hubbub sound, forest sound, and traffic noise were significantly higher than with the silent control condition (Figure 4(a)). ANOVA revealed a significant main effect for the mean oxy-Hb concentration change. The main effect of environmental sounds suggests that notable increases of oxy-Hb occurred during the serial arithmetic task compared to silence in Channel $2(F=3.076$, d.f. $=3, p<0.05)$, Channel $4(F=3.662$, d.f. $=3, p<0.05)$, Channel $7(F=2.820$, d.f. $=3, p<0.05)$, and channel $9(F=4.017$, d.f. $=3, p<0.05)$. On the other hand, there were no significant differences in the mean values in the right frontal cortex in Channels 13, 16, 18, 21 at a symmetrical position to Channels 2, 4, 7, 9 (Figure 4(b)).

\section{Discussion}

In terms of cognitive and performance outcomes, there is strong evidence that short-term noise exposure negatively affects cognitive functioning, especially attention (Tomei et al., 2006; Trimmel \& Poelzl, 2006). It is known that the prefrontal region is related to attention to tasks (Jueptner et al., 1997). However, it is not known whether short-term exposure to environmental sounds facilitates or obstructs mental task performance. Furthermore, there is little information on regional cerebral blood flow that occurs in response to environmental sounds, and, to our knowledge, no studies have examined cortical responses in relation to environmental sounds and mental task performance. This study aimed to clarify the most suitable environment for mental task performance by clarifying cortical responses in relation to environmental sounds during mental task performance.

This study considered the nervous activity of the brain and the relation to oxy- $\mathrm{Hb}$, deoxy- $\mathrm{Hb}$, and total- $\mathrm{Hb}$. $\mathrm{Oxy}-\mathrm{Hb}$ is the most sensitive indicator of changes in regional cerebral blood flow in NIRS measurements (Hoshi et al., 2001). Regional cerebral blood flow assessed with positron emission tomography or fMRI mainly reflects neuronal, and more specifically, (pre-) synaptic activity (Jueptner \& Weiller, 1995). Our results suggest that environmental sounds increase neuronal activity compared with silence. We used a serial addition test as the task in the present study. Most subsequent mathematical processing tests have used addition and/or subtraction of single digits (Wetherell, 1996). Such a mathematical processing test was used mainly to assess mental workload (Chiles et al., 1979). It was suggested that the simple addition of two numbers entails specific processes (van Harskamp \& Cipolotti, 2001). One of them is the implementation of supporting arithmetic procedures like carrying. Carrying refers to breaking down the number (i.e., 5 into 2 and 3), bridging to 10, maintaining the first digit in working memory, and then adding the remaining addend to complete the calculation. According to the 


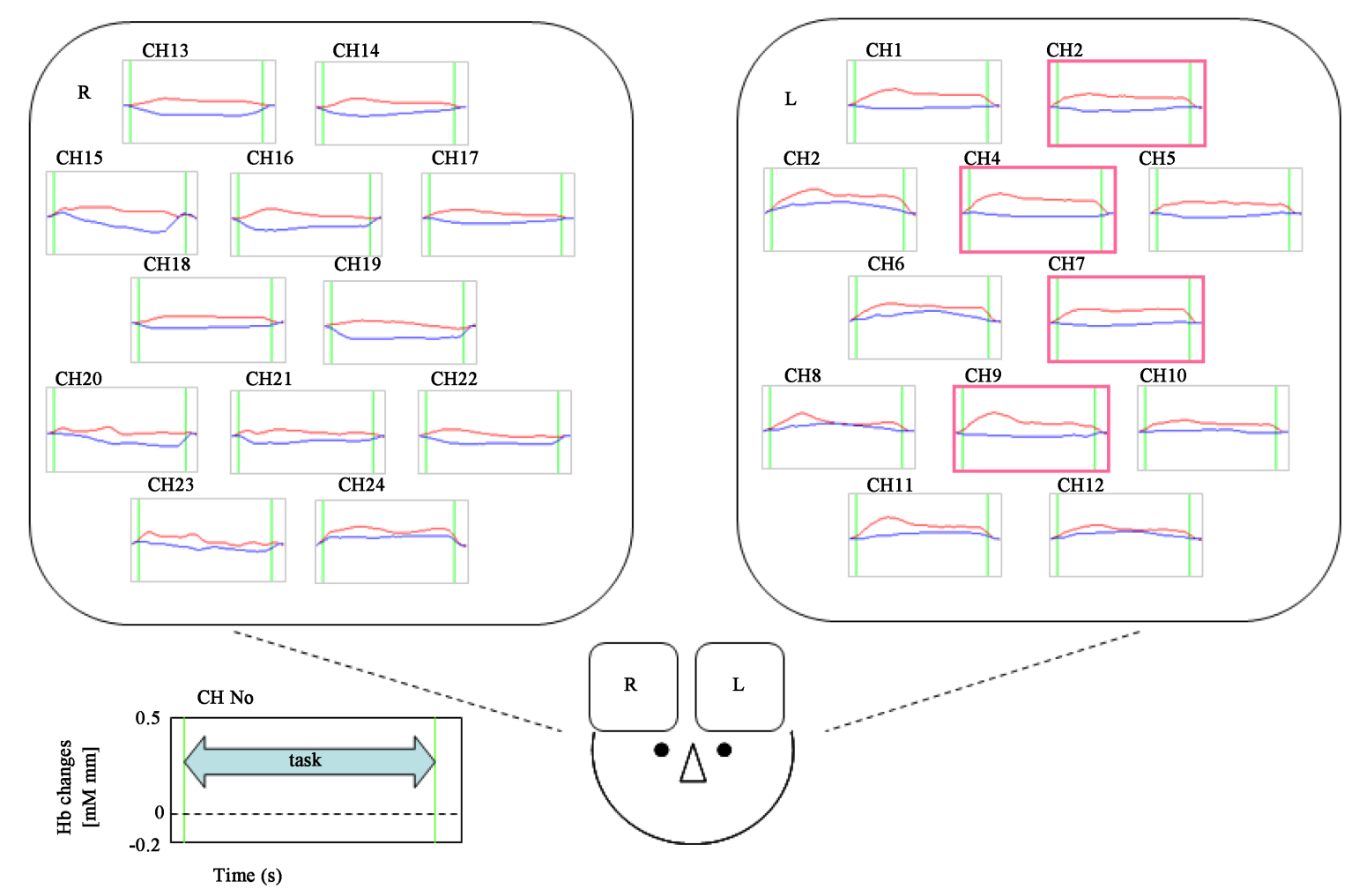

Figure 3. Grand averaged waveforms of oxygenated and deoxygenated hemoglobin concentration changes ([oxy-Hb], red line and [deoxy-Hb], blue line, respectively) in the forest sound during a 900 -s serial arithmetic task (between the two green lines) measured using the 24-channel NIRS machine over the frontal regions. The red frames indicate the channel showing significant higher hemodynamic peak changes compared to a silent control condition.

previous study (van Harskamp \& Cipolotti, 2001), working memory load seems to be influenced by the load of our task. Furthermore, in a previous study on mental arithmetic, it was reported that working memory load was accompanied by brain activation in inferior frontal areas as measured by fMRI (Ischebeck et al., 2009). Working memory-load-related increases in brain activation in the inferior frontal gyrus suggest increased attentional modulation in these brain regions during louder noises (Tomasi et al., 2005). These areas might have a general role for attention, and commonly activate during verbal and visuospatial working memory tasks (LaBar et al., 1999), as well as visual attention tasks (Chang et al., 2004). In addition, it was reported that the short-term noise exposure negatively affects cognitive functioning, especially attention (Tomei et al., 2006; Trimmel \& Poelzl, 2006). Therefore, environmental sounds might lead to an increased requirement for attentional modulation to perform a serial arithmetic task, causing corresponding increases in NIRS signals.

Interestingly, however, the performance under environmental sounds did not differ from performance under silence. These results are in contrast to those reported in a previous study, that showed a detrimental effect of sound (noise and music) on task performance compared with silence (Cassidy \& MacDonald, 2007). This difference may be due to the difference type of tasks examined in our studies. For example, the two-part Stroop Neuropsychological Screening Test, the Rivermead Behavioural Memory Test, and the free recall task consisting of 20 everyday six-letter words were assessed as cognitive tasks in a previous study (Cassidy \& MacDonald, 2007), whereas a serial arithmetic task was used in the present study. In the present study, all subjects were required to perform a serial arithmetic task according to the Uchida-Kraepelin performance test. The UchidaKraepelin test has been widely used in clinical psychology, psychiatry, and occupational mental health practice in Japan (Kato et al., 1999; Kurahashi et al., 1957; Yamada, 1996). Therefore, a serial arithmetic task was suitable to evaluate whether students exposed to environmental sounds might show significant differences in neuro-psychological profiles. The Uchida-Kraepelin performance test requires focused effort and attention by the subject, making this test useful for the assessment of mental stress (Li et al., 2004; Negoescu et al., 1997). 

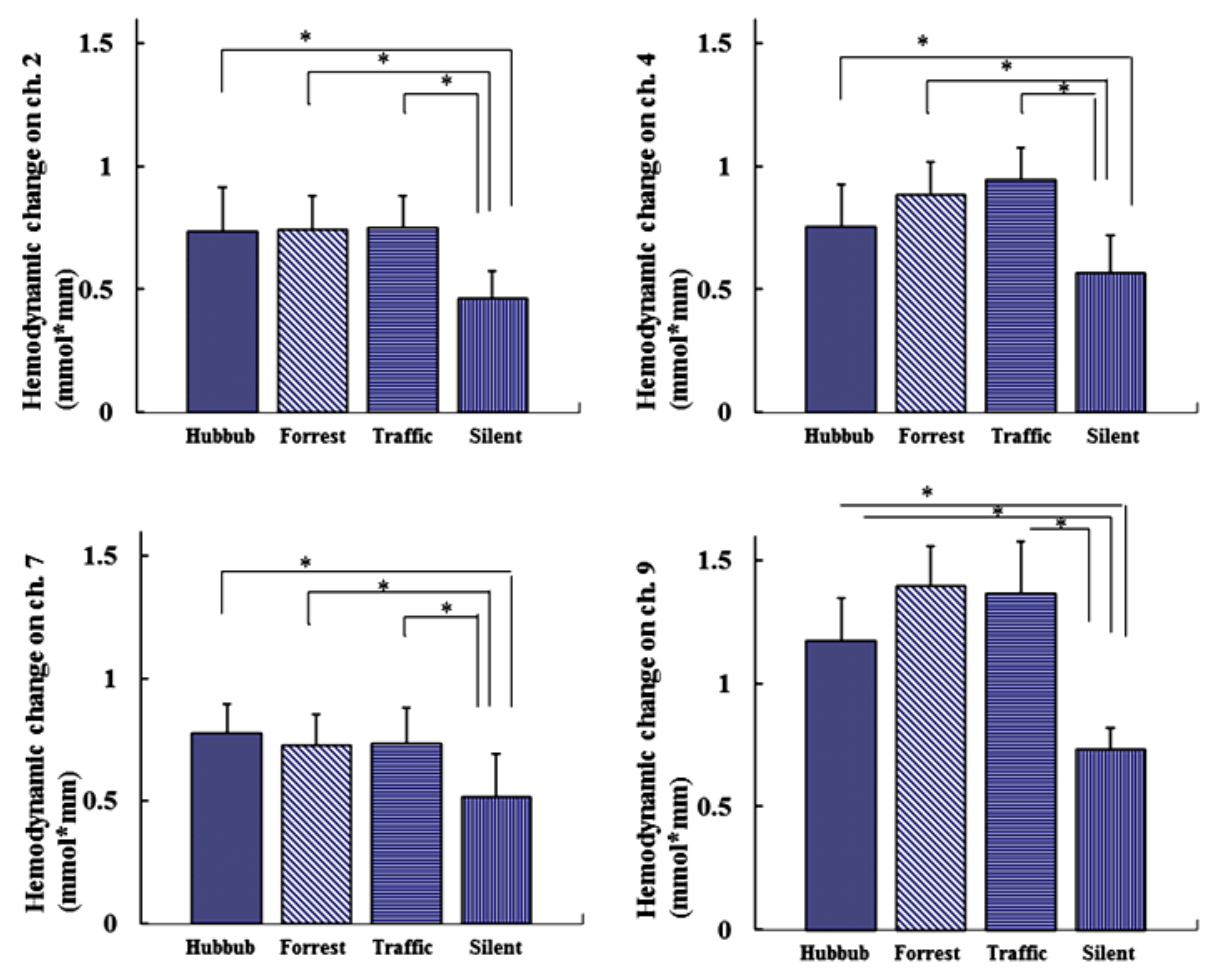

(a)
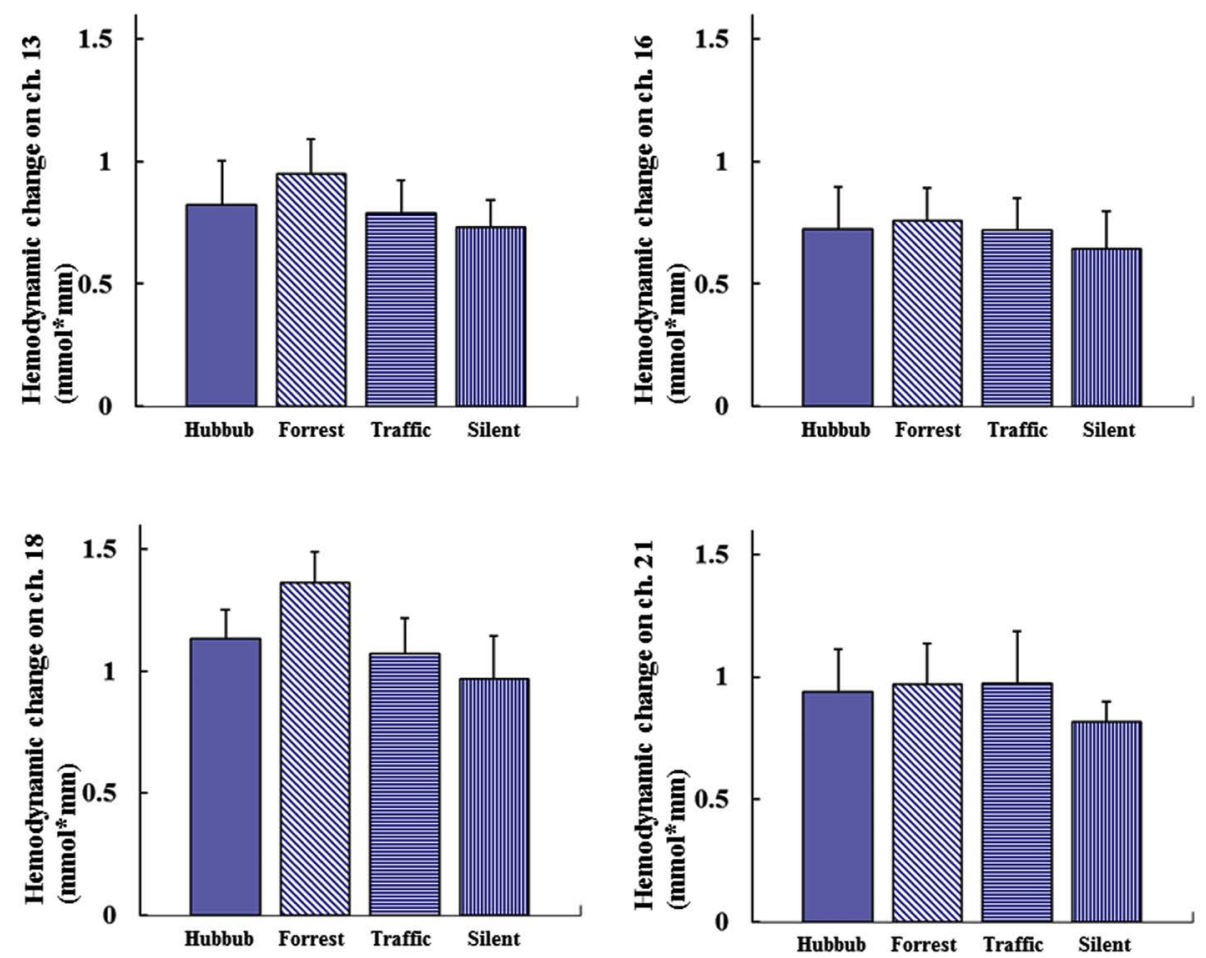

(b)

Figure 4. (a) The changes in oxy-Hb level in the serial arithmetic task in left side of frontal cortex. The means \pm SD of Channel 2, 4, 7, 9 are shown. The mean values in the hubbub sound, the forest sound and the traffic noise were significantly higher than those in the silent control conditions $\left({ }^{*} p<0.05\right)$. (b) The changes in oxy-Hb level in the serial arithmetic task in right side of frontal cortex. The means \pm SD of Channel 13, 16, 18, 21 are shown. No significant differences in hemodynamic change were seen between groups. 
Although we thought that attention and mental stress would strongly influence our results, there were no significant differences in the mean number of correct answers per line in any sound condition. Another study that reported the effect of noise on attention examined differences in the distracting noise at a either a relatively high volume ( $85 \mathrm{~dB})$ or a low volume $(75 \mathrm{~dB})$, which is meant to simulate what a person may experience in a crowd in a busy urban setting (Tregellas et al., 2012). In contrast, the volume of the environmental sound used in our study was $50 \mathrm{~dB}$, which is around the sound level of "quiet” outdoor courtyards. Gidlöf-Gunnarsson's study suggested the influence of the physical environmental quality (degree of naturalness) and utilization of "quiet" outdoor courtyards (defined as $L_{\text {Aeq,24h }} \leq 48 \mathrm{~dB}$, façade reflex included) in a sample of 385 residents (Gidlof-Gunnarsson \& Ohrstrom, 2010). They found that access to a "high quality" quiet courtyard was associated with less noise annoyance among the residents. In addition, Fuchino's study concluded that fMRI acoustic noise has an influence on the left hemisphere at the highest sound pressure level (65 dB); however, hemodynamic changes did not differ significantly between the non-noise condition and the two lower noise levels (46 $\mathrm{dB}, 56 \mathrm{~dB}$ ) in their study (Fuchino et al., 2006). In other words, it is likely that the sound level around $50 \mathrm{~dB}$ did not influence emotion. Furthermore, it is likely that the sound level of $50 \mathrm{~dB}$ was not high enough to facilitate hemodynamics changes. Therefore, to exclude the influence of the sound itself on emotion or hemodynamics changes, we chose environmental sounds of $50 \mathrm{~dB}$ in the present study. However, future studies should test different volumes of both pleasant and unpleasant sounds.

We showed that groups under environments with noise had greater increases in oxy-Hb levels in many frontal cortical regions. Previous studies on the influence of noise on attention have demonstrated that low-intensity background noise is associated with energy consumption, and that impaired performance in spatial attention or long-term exposure to noise has long-lasting detrimental effects on attention control (Kujala et al., 2004; Trimmel \& Poelzl, 2006). Trimmel's research suggested that noise-related changes reflect mental processes related to perceptual defense, which in turn consume mental resources (Trimmel \& Poelzl, 2006). Consistent with these previous studies, results of our study also showed that the frontal cortical regions showed a greater increase in oxy-Hb levels during the task in noisy environments in healthy subjects.

Evidence from brain-imaging studies indicates that parietal lobe areas are central in calculating and processing of numbers (Dehaene, 1992; Dehaene et al., 2003), whereas the frontal lobe areas are involved in recalling numerical knowledge and working memory (Dehaene, 1992; Wu et al., 2009). The present study showed the lateral dominance of extensive activation in arithmetic tasks. A previous study showed that for the superior temporal gyrus, inferior frontal gyrus, and thalamus, there was extensive left-hemispheric activation for addition tasks but not for subtraction tasks (Abd Hamid et al., 2011). The arithmetic task in our study centered on addition. Our results showing extensive activation in the left frontal lesion correspond to these previous studies.

The present study had several limitations. First, physiological effects were not assessed. A previous study showed that blood pressure and heart rate were positively correlated with noise level (dB) for industrial laborers, showing the undesirable effects of noise on cardiovascular health during work (Lusk et al., 2004). Noise may also have a positive effect on performance. As the cardiovascular system becomes activated, so does the cognitive system, to a certain degree. Studies have shown that during low mental load tasks, noise can have a positive effect on performance (Stansfeld et al., 2005). Second, noise can have a strong effect on performance (Stansfeld et al., 2005), especially for noise-sensitive individuals (Weinstein, 1978). For these persons, performance during noise exposure is lowered (Pawlaczyk-Luszczyniska et al., 2005; Sandrock et al., 2009; Waye et al., 2002), indicating the importance of controlling for noise sensitivity. In our study, noise sensitivity was not controlled. Third, underlying processes were not conducted in our study. A major challenge is to connect the effects of noise and cognitive performance with the many short-term experimental effects shown in various studies (Chiovenda et al., 2007; Westman \& Walters, 1981). One main concern is the focus in mainstream psychology on group comparisons rather than investigation of underlying processes (Bergman \& Magnusson, 1997). To assess this problem, a more advanced mathematical framework needs to be applied, especially as many areas of psychology are heading into research focused on biological processes that interact with and create various psychological phenomena. Considering these problems, it is thought that there were no differences between groups in our study because we adopted a serial arithmetic task as a method.

The detrimental effects of noise on attention have long been established in humans (Smith, 1991). This study aimed to evaluate if students exposed to environmental sounds, including urban traffic noise, might show significant differences in neuro-psychological profiles. The noise environments in our study had significantly different effects on the activation positions in the frontal cortex, demonstrating that low intensity background noise 
is associated with energy consumption expressed as an increase of blood flow volume. In other words, the results of the present study suggest that the task of addition performed under the presence of environmental sounds (compared with quiet) promoted apparent extended activation of the prefrontal cortex in regard to more attention required (expressed as energy consumption). Furthermore, apparent extended activation was shown in the left hemisphere of the brain in the present study. However, extended activation in the frontal cortex did not impact results of a serial arithmetic task. Future studies are needed to clarify these findings.

\section{References}

Abd Hamid, A. I., Yusoff, A. N., Mukari, S. Z., \& Mohamad, M. (2011). Brain Activation during Addition and Subtraction Tasks In-Noise and In-Quiet. Malaysian Journal of Medical Sciences, 18, 3-15.

Annerstedt, M., Jonsson, P., Wallergard, M., Johansson, G., Karlson, B., Grahn, P., Hansen, A. M., \& Wahrborg, P. (2013). Inducing Physiological Stress Recovery with Sounds of Nature in a Virtual Reality Forest-Results from a Pilot Study. Physiology \& Behavior, 118, 240-250. http://dx.doi.org/10.1016/j.physbeh.2013.05.023

Arsalidou, M., \& Taylor, M. J. (2011). Is $2+2=4$ ? Meta-Analyses of Brain Areas Needed for Numbers and Calculations. Neuroimage, 54, 2382-2393. http://dx.doi.org/10.1016/j.neuroimage.2010.10.009

Babisch, W. (2005). Noise and Health. Environmental Health Perspectives, 113, A14-15. http://dx.doi.org/10.1289/ehp.113-a14

Babisch, W., Beule, B., Schust, M., Kersten, N., \& Ising, H. (2005). Traffic Noise and Risk of Myocardial Infarction. Epidemiology, 16, 33-40. http://dx.doi.org/10.1097/01.ede.0000147104.84424.24

Banbury, S. (1998). Disruption of Office-Related Tasks by Speech and Office Noise. British Journal of Psychology, 89, 499-517. http://dx.doi.org/10.1111/j.2044-8295.1998.tb02699.x

Bergman, L. R., \& Magnusson, D. (1997). A Person-Oriented Approach in Research on Developmental Psychopathology. Development and Psychopathology, 9, 291-319. http://dx.doi.org/10.1017/S095457949700206X

Blood, A. J., \& Zatorre, R. J. (2001). Intensely Pleasurable Responses to Music Correlate with Activity in Brain Regions Implicated in Reward and Emotion. Proceedings of the National Academy of Sciences of the United States of America, 98, 11818-11823. http://dx.doi.org/10.1073/pnas.191355898

Bluhm, G., Nordling, E., \& Berglind, N. (2004). Road Traffic Noise and Annoyance-An Increasing Environmental Health Problem. Noise Health, 6, 43-49.

Boly, M., Faymonville, M. E., Peigneux, P., Lambermont, B., Damas, P., Del Fiore, G., Degueldre, C., Franck, G., Luxen, A., Lamy, M., Moonen, G., Maquet, P., \& Laureys, S. (2004). Auditory Processing in Severely Brain Injured Patients: Differences between the Minimally Conscious State and the Persistent Vegetative State. Archives of Neurology, 61, $233-238$. http://dx.doi.org/10.1001/archneur.61.2.233

Cassidy, G., \& MacDonald, R. (2007). The Effect of Background Music and Background Noise on the Task Performance of Introverts and Extraverts. Psychology of Music, 35, 517-537. http://dx.doi.org/10.1177/0305735607076444

Chang, L., Tomasi, D., Yakupov, R., Lozar, C., Arnold, S., Caparelli, E., \& Ernst, T. (2004). Adaptation of the Attention Network in Human Immunodeficiency Virus Brain Injury. Annals of Neurology, 56, 259-272. http://dx.doi.org/10.1002/ana.20190

Chiles, W. D., Jennings, A. E., \& Alluisi, E. A. (1979). Measurement and Scaling of Workload in Complex Performance. Aviation, Space, and Environmental Medicine, 50, 376-381.

Chiovenda, P., Pasqualetti, P., Zappasodi, F., Ercolani, M., Milazzo, D., Tomei, G., Capozzella, A., Tomei, F., Rossini, P. M., \& Tecchio, F. (2007). Environmental Noise-Exposed Workers: Event-Related Potentials, Neuropsychological and Mood Assessment. International Journal of Psychophysiology, 65, 228-237. http://dx.doi.org/10.1016/j.ijpsycho.2007.04.009

Cui, X., Bray, S., \& Reiss, A. L. (2010). Functional near Infrared Spectroscopy (NIRS) Signal Improvement Based on Negative Correlation between Oxygenated and Deoxygenated Hemoglobin Dynamics. Neuroimage, 49, 3039-3046.

http://dx.doi.org/10.1016/j.neuroimage.2009.11.050

Dehaene, S. (1992). Varieties of Numerical Abilities. Cognition, 44, 1-42. http://dx.doi.org/10.1016/0010-0277(92)90049-N

Dehaene, S., Piazza, M., Pinel, P., \& Cohen, L. (2003). Three Parietal Circuits for Number Processing. Cognitive Neuropsychology, 20, 487-506. http://dx.doi.org/10.1080/02643290244000239

Engelien, A., Huber, W., Silbersweig, D., Stern, E., Frith, C. D., Doring, W., Thron, A., \& Frackowiak, R. S. (2000). The Neural Correlates of "Deaf-Hearing" in Man: Conscious Sensory Awareness Enabled by Attentional Modulation. Brain, 123, 532-545. http://dx.doi.org/10.1093/brain/123.3.532

Falk, T., Paton, K., Power, S., \& Chau, T. (2010). Improving the Performance of NIRS-Based Brain-Computer Interfaces in 
the Presence of Background Auditory Distractions. International Conference on Acoustics, Speech, and Signal Processing, 14-19 March 2010, Dallas, 517-520.

Flaten, M. A., Nordmark, E., \& Elden, A. (2005). Effects of Background Noise on the Human Startle Reflex and Prepulse Inhibition. Psychophysiology, 42, 298-305. http://dx.doi.org/10.1111/j.1469-8986.2005.00293.X

Fuchino, Y., Sato, H., Maki, A., Yamamoto, Y., Katura, T., Obata, A., Koizumi, H., \& Yoro, T. (2006). Effect of fMRI Acoustic Noise on Sensorimotor Activation Examined Using Optical Topography. NeuroImage, 32, 771-777. http://dx.doi.org/10.1016/j.neuroimage.2006.04.197

Furnham, A., \& Strbac, L. (2002). Music Is as Distracting as Noise: The Differential Distraction of Background Music and Noise on the Cognitive Test Performance of Introverts and Extraverts. Ergonomics, 45, 203-217. http://dx.doi.org/10.1080/00140130210121932

Gidlof-Gunnarsson, A., \& Ohrstrom, E. (2010). Attractive “Quiet” Courtyards: A Potential Modifier of Urban Residents’ Responses to Road Traffic Noise? International Journal of Environmental Research and Public Health, 7, 3359-3375. http://dx.doi.org/10.3390/ijerph7093359

Gumenyuk, V., Korzyukov, O., Alho, K., Escera, C., \& Naatanen, R. (2004). Effects of Auditory Distraction on Electrophysiological Brain Activity and Performance in Children Aged 8 - 13 Years. Psychophysiology, 41, 30-36. http://dx.doi.org/10.1111/1469-8986.00123

Hoshi, Y., Kobayashi, N., \& Tamura, M. (2001). Interpretation of Near-Infrared Spectroscopy Signals: A Study with a Newly Developed Perfused Rat Brain Model. Journal of Applied Physiology, 90, 1657-1662.

Howard, C. S., Munro, K. J., \& Plack, C. J. (2010). Listening Effort at Signal-to-Noise Ratios that Are Typical of the School Classroom. International Journal of Audiology, 49, 928-932. http://dx.doi.org/10.3109/14992027.2010.520036

Ischebeck, A., Zamarian, L., Schocke, M., \& Delazer, M. (2009). Flexible Transfer of Knowledge in Mental Arithmetic-An fMRI Study. NeuroImage, 44, 1103-1112. http://dx.doi.org/10.1016/j.neuroimage.2008.10.025

Jarup, L., Dudley, M. L., Babisch, W., Houthuijs, D., Swart, W., Pershagen, G., Bluhm, G., Katsouyanni, K., Velonakis, M., Cadum, E., Vigna-Taglianti, F., \& Consortium, H. (2005). Hypertension and Exposure to Noise near Airports (HYENA): Study Design and Noise Exposure Assessment. Environmental Health Perspectives, 113, 1473-1478. http://dx.doi.org/10.1289/ehp.8037

Jueptner, M., \& Weiller, C. (1995). Review: Does Measurement of Regional Cerebral Blood Flow Reflect Synaptic Activity? Implications for PET and fMRI. NeuroImage, 2, 148-156. http://dx.doi.org/10.1006/nimg.1995.1017

Jueptner, M., Stephan, K. M., Frith, C. D., Brooks, D. J., Frackowiak, R. S., \& Passingham, R. E. (1997). Anatomy of Motor Learning. I. Frontal Cortex and Attention to Action. Journal of Neurophysiology, 77, 1313-1324.

Kato, T., Murashita, J., Shioiri, T., Inubushi, T., \& Kato, N. (1999). Relationship of Energy Metabolism Detected by ${ }^{31} \mathrm{P}-\mathrm{MRS}$ in the Human Brain with Mental Fatigue. Neuropsychobiology, 39, 214-218. http://dx.doi.org/10.1159/000026587

Kujala, T., Shtyrov, Y., Winkler, I., Saher, M., Tervaniemi, M., Sallinen, M., Teder-Salejarvi, W., Alho, K., Reinikainen, K., \& Naatanen, R. (2004). Long-Term Exposure to Noise Impairs Cortical Sound Processing and Attention Control. Psychophysiology, 41, 875-881. http://dx.doi.org/10.1111/j.1469-8986.2004.00244.X

Kurahashi, S., Kato, M., \& Tsujioka, B. (1957). Development of the Uchida-Kraepelin Psychodiagnostic Test in Japan. Psychologia (Kyoto), 1, 104-109.

LaBar, K. S., Gitelman, D. R., Parrish, T. B., \& Mesulam, M. (1999). Neuroanatomic Overlap of Working Memory and Spatial Attention Networks: A Functional MRI Comparison within Subjects. NeuroImage, 10, 695-704. http://dx.doi.org/10.1006/nimg.1999.0503

Li, G. Y., Ueki, H., Kawashima, T., Sugataka, K., Muraoka, T., \& Yamada, S. (2004). Involvement of the Noradrenergic System in Performance on a Continuous Task Requiring Effortful Attention. Neuropsychobiology, 50, 336-340. http://dx.doi.org/10.1159/000080962

Lundquist, P., Holmberg, K., \& Landstrom, U. (2000). Annoyance and Effects on Work from Environmental Noise at School. Noise \& Health, 2, 39-46.

Lusk, S. L., Gillespie, B., Hagerty, B. M., \& Ziemba, R. A. (2004). Acute Effects of Noise on Blood Pressure and Heart Rate. Archives of Environmental Health, 59, 392-399. http://dx.doi.org/10.3200/AEOH.59.8.392-399

Luu, S., \& Chau, T. (2009). Decoding Subjective Preference from Single-Trial Near-Infrared Spectroscopy Signals. Journal of Neural Engineering, 6, Article ID: 016003. http://dx.doi.org/10.1088/1741-2560/6/1/016003

Maki, A., Yamashita, Y., Ito, Y., Watanabe, E., Mayanagi, Y., \& Koizumi, H. (1995). Spatial and Temporal Analysis of Human Motor Activity Using Noninvasive NIR Topography. Medical Physics, 22, 1997-2005. http://dx.doi.org/10.1118/1.597496

Negoescu, R., Dinca-Panaitescu, S., Filcescu, V., Ionescu, D., \& Wolf, S. (1997). Mental Stress Enhances the Sympathetic 
Fraction of QT Variability in an RR-Independent Way. Integrative Physiological and Behavioral Science, 32, $220-227$. http://dx.doi.org/10.1007/BF02688620

Okada, E., \& Delpy, D. T. (2003). Near-Infrared Light Propagation in an Adult Head Model. II. Effect of Superficial Tissue Thickness on the Sensitivity of the Near-Infrared Spectroscopy Signal. Applied Optics, 42, 2915-2922. http://dx.doi.org/10.1364/AO.42.002915

Okamoto, M., Dan, H., Sakamoto, K., Takeo, K., Shimizu, K., Kohno, S., Oda, I., Isobe, S., Suzuki, T., Kohyama, K., \& Dan, I. (2004). Three-Dimensional Probabilistic Anatomical Cranio-Cerebral Correlation via the International 10-20 System Oriented for Transcranial Functional Brain Mapping. NeuroImage, 21, 99-111. http://dx.doi.org/10.1016/j.neuroimage.2003.08.026

Oldfield, R. C. (1971). The Assessment and Analysis of Handedness: The Edinburgh Inventory. Neuropsychologia, 9, 97113. http://dx.doi.org/10.1016/0028-3932(71)90067-4

Pawlaczyk-Luszczyniska, M., Dudarewicz, A., Waszkowska, M., Szymczak, W., \& Sliwinska-Kowalska, M. (2005). The Impact of Low-Frequency Noise on Human Mental Performance. International Journal of Occupational Medicine and Environmental Health, 18, 185-198.

Saadatmand, V., Rejeh, N., Heravi-Karimooi, M., Tadrisi, S. D., Zayeri, F., Vaismoradi, M., \& Jasper, M. (2013). Effect of Nature-Based Sounds' Intervention on Agitation, Anxiety, and Stress in Patients under Mechanical Ventilator Support: A Randomised Controlled Trial. International Journal of Nursing Studies, 50, 895-904. http://dx.doi.org/10.1016/j.ijnurstu.2012.11.018

Salisbury, D. F., Desantis, M. A., Shenton, M. E., \& McCarley, R. W. (2002). The Effect of Background Noise on P300 to Suprathreshold Stimuli. Psychophysiology, 39, 111-115. http://dx.doi.org/10.1111/1469-8986.3910111

Sandrock, S., Schutte, M., \& Griefahn, B. (2009). Impairing Effects of Noise in High and Low Noise Sensitive Persons Working on Different Mental Tasks. International Archives of Occupational and Environmental Health, 82, 779-785. http://dx.doi.org/10.1007/s00420-008-0379-0

Sitaram, R., Zhang, H., Guan, C., Thulasidas, M., Hoshi, Y., Ishikawa, A., Shimizu, K., \& Birbaumer, N. (2007). Temporal Classification of Multichannel Near-Infrared Spectroscopy Signals of Motor Imagery for Developing a Brain-Computer Interface. NeuroImage, 34, 1416-1427. http://dx.doi.org/10.1016/j.neuroimage.2006.11.005

Smith, A. P. (1991). Noise and Aspects of Attention. British Journal of Psychology, 82, 313-324. http://dx.doi.org/10.1111/j.2044-8295.1991.tb02402.x

Stansfeld, S. A., Berglund, B., Clark, C., Lopez-Barrio, I., Fischer, P., Ohrstrom, E., Haines, M. M., Head, J., Hygge, S., van Kamp, I., Berry, B. F. on Behalf of the RANCH Study Team (2005). Aircraft and Road Traffic Noise and Children's Cognition and Health: A Cross-National Study. Lancet, 365, 1942-1949.

http://dx.doi.org/10.1016/S0140-6736(05)66660-3

Strangman, G., Culver, J. P., Thompson, J. H., \& Boas, D. A. (2002). A Quantitative Comparison of Simultaneous BOLD fMRI and NIRS Recordings during Functional Brain Activation. NeuroImage, 17, 719-731. http://dx.doi.org/10.1006/nimg.2002.1227

Sugimoto, K., Kanai, A., \& Shoji, N. (2009). The Effectiveness of the Uchida-Kraepelin Test for Psychological Stress: An Analysis of Plasma and Salivary Stress Substances. BioPsychoSocial Medicine, 3, 5. http://dx.doi.org/10.1186/1751-0759-3-5

Tomasi, D., Caparelli, E. C., Chang, L., \& Ernst, T. (2005). fMRI-Acoustic Noise Alters Brain Activation during Working Memory Tasks. NeuroImage, 27, 377-386. http://dx.doi.org/10.1016/j.neuroimage.2005.04.010

Tomei, G., Tecchio, F., Zappasodi, F., Ercolani, M., Moffa, F., Chiovenda, P., \& Ciarrocca, M. (2006). Exposure to Traffic Noise and Effects on Attention. Annali di Igiene, 18, 507-519.

Tregellas, J. R., Smucny, J., Eichman, L., \& Rojas, D. C. (2012). The Effect of Distracting Noise on the Neuronal Mechanisms of Attention in Schizophrenia. Schizophrenia Research, 142, 230-236. http://dx.doi.org/10.1016/j.schres.2012.09.008

Trimmel, M., \& Poelzl, G. (2006). Impact of Background Noise on Reaction Time and Brain DC Potential Changes of VDT-Based Spatial Attention. Ergonomics, 49, 202-208. http://dx.doi.org/10.1080/00140130500434986

van Harskamp, N. J., \& Cipolotti, L. (2001). Selective Impairments for Addition, Subtraction and Multiplication. Implications for the Organisation of Arithmetical Facts. Cortex, 37, 363-388. http://dx.doi.org/10.1016/S0010-9452(08)70579-3

Villringer, A., \& Chance, B. (1997). Non-Invasive Optical Spectroscopy and Imaging of Human Brain Function. Trends in Neurosciences, 20, 435-442. http://dx.doi.org/10.1016/S0166-2236(97)01132-6

Watanabe, A., Kato, N., \& Kato, T. (2002). Effects of Creatine on Mental Fatigue and Cerebral Hemoglobin Oxygenation. Neuroscience Research, 42, 279-285. http://dx.doi.org/10.1016/S0168-0102(02)00007-X

Waye, K. P., Bengtsson, J., Rylander, R., Hucklebridge, F., Evans, P., \& Clow, A. (2002). Low Frequency Noise Enhances Cortisol among Noise Sensitive Subjects during Work Performance. Life Sciences, 70, 745-758. 
http://dx.doi.org/10.1016/S0024-3205(01)01450-3

Weinstein, N. D. (1978). Individual Differences in Reactions to Noise: A Longitudinal Study in a College Dormitory. Journal of Applied Psychology, 63, 458-466. http://dx.doi.org/10.1037/0021-9010.63.4.458

Westman, J. C., \& Walters, J. R. (1981). Noise and Stress: A Comprehensive Approach. Environmental Health Perspectives, 41, 291-309. http://dx.doi.org/10.1289/ehp.8141291

Wetherell, A. (1996). Performance Tests. Environmental Health Perspectives, 104, 247-273. http://dx.doi.org/10.1289/ehp.96104s2247

Wu, S. S., Chang, T. T., Majid, A., Caspers, S., Eickhoff, S. B., \& Menon, V. (2009). Functional Heterogeneity of Inferior Parietal Cortex during Mathematical Cognition Assessed with Cytoarchitectonic Probability Maps. Cerebral Cortex, 19, 2930-2945. http://dx.doi.org/10.1093/cercor/bhp063

Yamada, K. (1996). The Uchida-Kraepelin Psychodiagnostic Test Text. Tokyo: Psychotechnological Institute of Japan, Inc. 
Scientific Research Publishing (SCIRP) is one of the largest Open Access journal publishers. It is currently publishing more than 200 open access, online, peer-reviewed journals covering a wide range of academic disciplines. SCIRP serves the worldwide academic communities and contributes to the progress and application of science with its publication.

Other selected journals from SCIRP are listed as below. Submit your manuscript to us via either submit@scirp.org or Online Submission Portal.
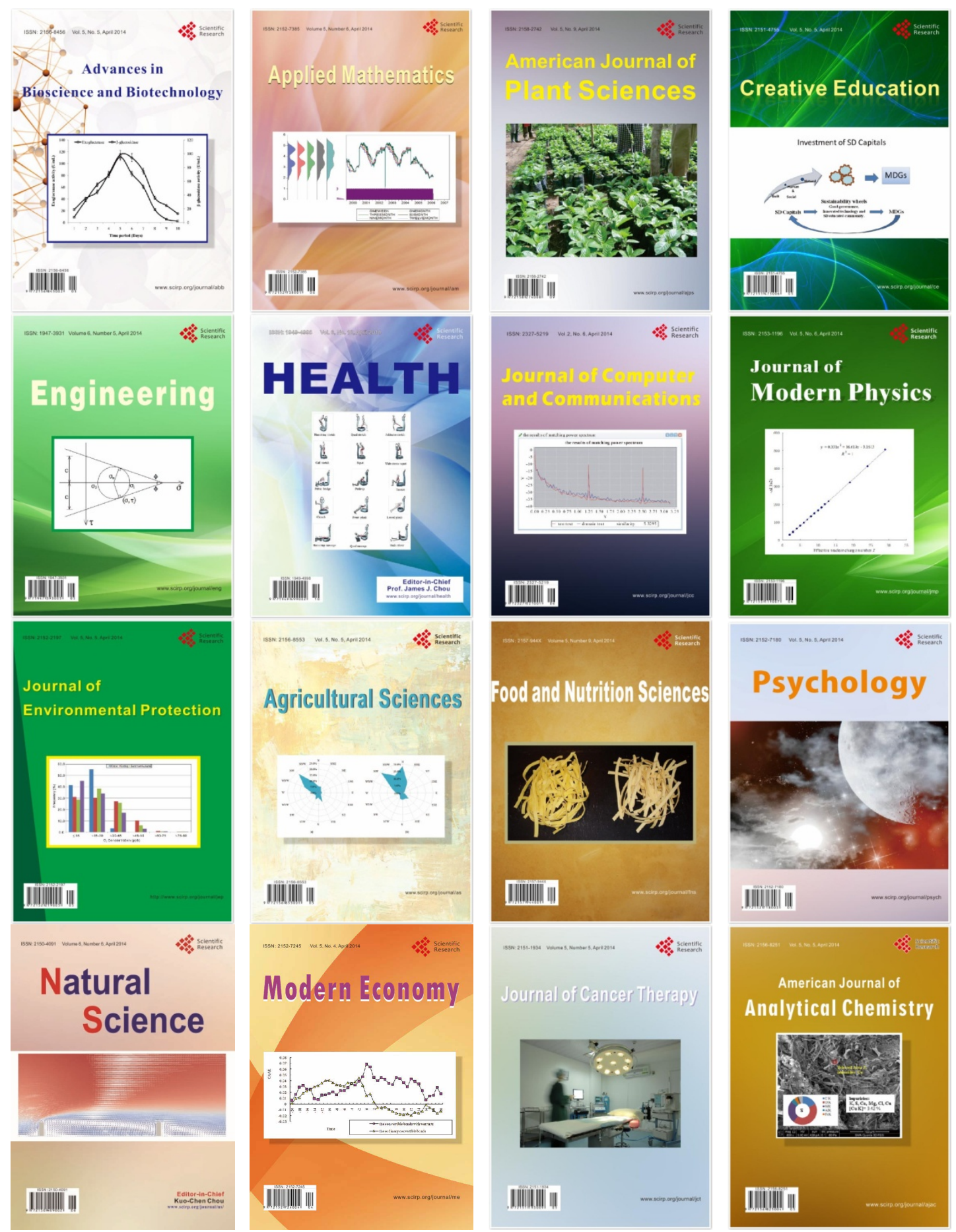